\title{
Dimensioning the Irrigation Variables for Table Grape Vineyards in Litho-soils
}

\author{
Pasquale Campi*, Francesca Modugno, Domenico A. Palumbo, Marcello Mastrorilli \\ CRA - Research Unit for Cropping Systems in Hot-Dry Environments \\ Via C. Ulpiani 5, 70125 Bari, Italy
}

Received: 14 September 2009. Accepted: 14 April 2010.

\begin{abstract}
The pedo-climatic and farm characteristics of Bari's hinterland have allowed for the diffusion of prestigious table viticulture.

The typical "tendone" vineyard structure is set up after managing the surface of the soil. The karstic nature of the region and the thermo-rainfall trend during the vegetative season impede the vineyard from producing adequately without irrigation. Given the importance of water contributions to table grapes, it is necessary to correctly measure the water variables for economic and environmental reasons.

Farmers often irrigate according to "fixed" turns and volumes, against the rules of "good irrigation practice" which consider monitoring the water status of the soil or plant as a prerequisite of irrigation scheduling.

During this experiment, two methods of irrigation management were compared: "fixed-turn" and "on demand". For "on demand" irrigation, the irrigation volume is calculated on the basis of the soil water status (estimated according to the "water balance" method described in the "Paper n. 56 FAO") and the irrigation is scheduled on the basis of the experimental relationship between "pre-dawn" leaf water potential and the water available in the soil. For this comparison, data from a 2-year "on farm" experimentation, in an area typical of table grape cultivation in Southern Italy, have been used.

The results obtained show that, in respect to the "fixed-turn" management, the "on demand" management allows for a $20 \%$ reduction in water volumes, without compromising production. The water balance method proved to be a promising criterion for irrigation scheduling in these shallow soils, rich in stones (litho-soils). This only held true when the depth of the soil layer explored by the root system was defined by the "equivalent depth" and not by the actual soil's depth.
\end{abstract}

Key-words: water balance, evapo-transpiration, karstic soil, pre-dawn leaf water potential, plant water status, soil water content.

\section{Introduction}

The karstic nature and typical climatic conditions of Bari's hinterland, such as temperature, radiation and air humidity, have allowed for the diffusion of a prestigious table viticulture (Colapietra, 2004) even in marginal soils such as alfi-soils, rich in stones, from the Pre-Murgiana area.

On the contrary, the rainfall patterns in the area create a water deficit which extends from spring until the beginning of autumn. The scarce availability of natural water resources impedes the table grape vineyard from adequately producing without irrigating.

Given the importance of water contributions to table grapes, it is necessary to correctly measure the irrigation variables for economic and environmental reasons. In the case of litho-soils, measuring irrigation variables (which include mainly the beginning and the duration of the irrigation season, irrigation volumes and turns) is complex (Palumbo et al., 2007).

The vines, typically grown in the "tendone" training system, are planted after arranging the soil surface which generally calls for "trenching" 
at the depth of $0.5 \mathrm{~m}$, followed by shattering the rocks in loco. The result is a litho-soil characterized by a surface layer rich in stones and a subsoil characterized by calcareous cracked rock.

In such conditions, sampling the humidity of the soil or installing sensors in the soil, allows one to determine the water status until a depth of about $0.5 \mathrm{~m}$. It is not possible to take measurements beyond this depth due to the presence of limestone rock. The roots of the grapevine, however, are not limited by this rock bank. In fact, they slip inside the cracks of the calcareous rock layer, where sacks of clay soil conserve a large amount of the humidity and mineral elements that are necessary to sustain productivity of the vineyard.

The extreme irregularity in these sack distributions and capacity to retain water make their identification and modelling complex. As a consequence, calculating the soil contribution the vineyard water requirement when it is deeper than $0.5 \mathrm{~m}$ proves to be impossible.

Operatively, irrigation planning can be carried out with a water balance which has to consider the depth of the soil volume explored by the root system not on the basis of the actual depth but of the whole explored layer of soil, excluding the stones.

For many farmers, however, irrigation planning is impeded by its restriction to "fixed-turn" irrigation management which calls for fixed volumes and turns, and overlooks the water status of the soil or vegetation.

The paper aims to a compare two irrigation water managements ("fixed-turn" and "on demand") on farms specialized in growing table grape. The comparison concerns the irrigation variables which were directly measured in field or simulated trough the soil water balance approach adapted to the litho-soils. The analysis of the results obtained allows to provide some operative indications about the dimensioning of irrigation variables in litho-soils.

\section{Materials and methods}

The experimental activity was preformed in 2005 and 2006 on a private farm (4 ha), located in an area represented by table grape cultivation (Rutigliano - Bari, lat. 4059', long. $17^{\circ} 59^{\prime}$, alt. $147 \mathrm{~m}$ a.s.1.).

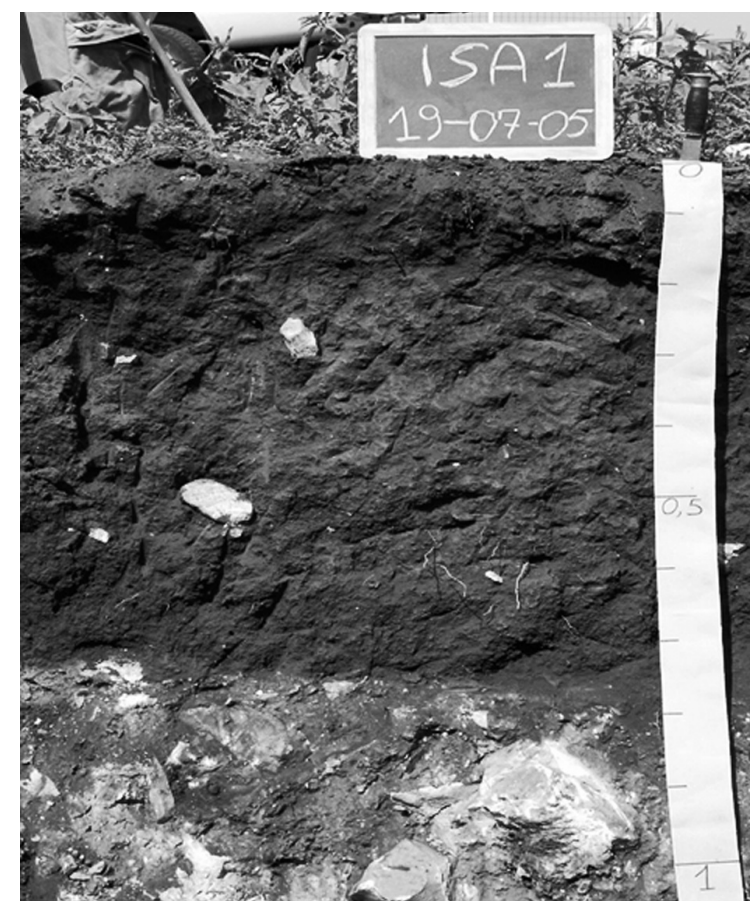

Figure 1. Profile of the soil.

The table grape vineyard ( $c v$ "Italia" grafted on "P 1103"), growing in horizontal canopy on overhead trellis (tendone), was installed in the year 2000, on a litho-soil (Rhodoxeralf Lithic Ruptic) typical of the Mediterranean area (Fig. 1), favourably reclaimed and characterized by a superficial clay layer $(0.5 \mathrm{~m})$ rich in stone $(22 \%)$ and a subsoil represented by calcareous cracked rock (Tab. 1).

On the same farm, two methods of irrigation scheduling were compared: "fixed-turn" (on a 3.5ha plot) and "on demand" (on 0.5ha). During the two watering seasons, on both plots, the following was estimated or measured:

- water potential in "pre-dawn" $(\Psi)$;

- water status of the soil using the gravimetric method;

- irrigation turns and volumes.

The measurement of $\Psi$ was performed with the Scholander pressure chamber on a sample of 6 youngest leaves that were completely expanded and cut near the base of the stalk. The water potential measurements were performed before sunrise when the stomata were still closed and transpiration was absent. In these conditions it can be presumed that the water potential of the plant is in equilibrium with the 
Table 1. Physical and chemical characteristics of soil in vineyard field (Rutigliano, Ba).

\begin{tabular}{lc}
\hline Physical and chemical characteristics & mean \\
\hline stone $(\%)(\varnothing>2 \mathrm{~mm})$ & $15 \pm 1.8$ \\
soil $(\%)(\varnothing<2 \mathrm{~mm})$ & $85 \pm 1.8$ \\
coarse sand $(\%)(0.2<\varnothing<2 \mathrm{~mm})$ & $4 \pm 0.4$ \\
fine sand $(\%)(0.05<\varnothing<0.2 \mathrm{~mm})$ & $17 \pm 0.8$ \\
coarse silt $(\%)(0.02<\varnothing<0.05 \mathrm{~mm})$ & $12 \pm 0.2$ \\
fine silt $(\%)(0.002<\varnothing<0.02 \mathrm{~mm})$ & $25 \pm 2.9$ \\
clay $(\%)(\varnothing<0.002 \mathrm{~mm})$ & $42 \pm 3.6$ \\
total limestone $(\%)$ & $2 \pm 0.0$ \\
active limestone $(\%)$ & $1 \pm 0.0$ \\
organic matter $($ Walkley and Balack) $(\%)$ & $1.4 \pm 0.1$ \\
EC 1:4 dSm ${ }^{-1}$ & $0.55 \pm 0.06$ \\
field capacity $(\%)$ & $26 \pm 0.3$ \\
wilting point $(\%)$ & $17 \pm 0.3$ \\
\hline
\end{tabular}

water potential of all the soil that had been explored by the roots.

The measurements taken according to the gravimetric method allow one to determine the evolution of the soil's water status up to a depth of $0.5 \mathrm{~m}$. Withdrawals are no longer possible beyond this depth due to the presence of a cracked calcareous rock bank which impedes sampletaking. The soil humidity was determined by samples weighing $3 \mathrm{~kg}$ each, taken from two layers of the soil profile. For every sample $(0.5 \mathrm{~m}$ in depth) the percentage (in weight and in volume) of the stones was determined (Tab. 2).

In the case of "fixed-turn" irrigation, in the two year course of experimentation, the farmer irrigated as usual in the region. Actually, irrigation was carried out with water made available by third parties, with irrigation volumes and turns prearranged by contract.

In the case of "on demand" irrigation, experimentation was carried out after having isolated a section of the water structure (0.5ha) within the private farm.

The irrigation water was scheduled on the basis of the plant water status, following the approach used for vineyards in other experimental conditions (Lebon et al., 2003; Pellegrino et al., 2004): the irrigation moment was deduced from the relationship between the plant's water status $(\Psi)$ and the available water (AW). This relationship enables for the recognition of the AW value which corresponds to the minimum value of $\Psi$. When this value is surpassed, the grapevine manifests symptoms of stress due to lack of water. The data from the field experiment, measured in 2005, has served to define the threshold value of TAW. This threshold value was used to pilot "on demand" irrigation in the following watering season (2006).

The meteorological data (rain, air temperature, relative humidity, net radiation and wind speed) were measured at the agrometeorological station realized near to experimental fields following the WMO standards (Doorenbos, 1976).

The irrigation volumes were obtained through the "water balance" method (Allen et al., 1998). For calculating the daily evapotranspiration (ETc) the "dual" crop coefficients (Kcdual ) was used. For calculating $\mathrm{Kc}_{\text {dual }}$ the tabulated values reported in the "Paper n. 56 FAO" were assumed $\left(\mathrm{Kc}_{\mathrm{ini}}: 0.15 ; \mathrm{Kc}_{\text {med }}: 0.9 ; \mathrm{Kc}_{\mathrm{end}}: 0.4\right)$. The water balance method was performed while taking into consideration two different soil depths: the depth relative to the reclamation $(0.5 \mathrm{~m})$ and the "equivalent depth" of $1 \mathrm{~m}$. In this case, one can hypothesize that the layer of explored soil by the roots of the rootstock "P1103" (Vitis berlandieri $\mathrm{x}$ Vitis rupestris, characterized by tight geo-tropic angle and resistance to drought) includes not only the layer of the trenched soil $(0.5 \mathrm{~m})$, but also the sacks of soil present in the cracked calcareous rock, excluding the stones.

When irrigation volumes (or rainfalls) are inadequate, the entire content of readily available water runs out (fraction of the total available water - TAW, p, which each species is able to uptake easily) and the plant is subjected to water stress conditions. Such conditions are ex-

Table 2. Percentages (on weight and on volume basis) of the stones divided for classes $(>16,16-8$ and $<8 \mathrm{~mm})$, in two layers of soil $(0-0.25 \mathrm{~m}$ and $0.26-0.5 \mathrm{~m})$.

\begin{tabular}{lcccccccc}
\hline Depth (m) & \multicolumn{3}{c}{$\varnothing>16 \mathrm{~mm}$} & \multicolumn{2}{c}{$8<\varnothing<16 \mathrm{~mm}$} & \multicolumn{2}{c}{$\varnothing<8 \mathrm{~mm}$} \\
\hline & weight & $(\%)$ & volume $(\%)$ & weight $(\%)$ & volume $(\%)$ & weight $(\%)$ & volume $(\%)$ \\
\hline $0-0.25$ & $32 \pm 7$ & $32 \pm 6$ & $30 \pm 3$ & $29 \pm 4$ & $38 \pm 5$ & $39 \pm 6$ \\
$0.26-0.5$ & $48 \pm 12$ & $45 \pm 14$ & $23 \pm 6$ & $24 \pm 7$ & $29 \pm 7$ & $32 \pm 8$ \\
\hline
\end{tabular}


pressed through the water stress coefficient $(\mathrm{Ks})$, calculated as the ratio between the water that is actually available (the difference between TAW and the water used by the crops, Ur) and the water that is readily available (Allen et al., 1998):

$$
K s=\frac{T A W-U_{r}}{(1-p) \cdot T A W}
$$

Ks varies from 1 (optimum water conditions) to 0 (maximum water stress) which happens when the entire contents of the TAW in the layer of soil where the roots are involved dries up.

A value of 0.5 for $p$ is commonly used for many crops.

\section{Results and discussion}

Irrigation volumes varied with each year. In particular, in the case of fixed-turn irrigation, during the year 2006 the farmer gave a higher irrigation volume $(296 \mathrm{~mm})$ than the year 2005 $(136 \mathrm{~mm})$ in order to affront a dryer year.

The water balance method taken from the FAO 56 notebook, carried out at $0.5 \mathrm{~m}$, high-

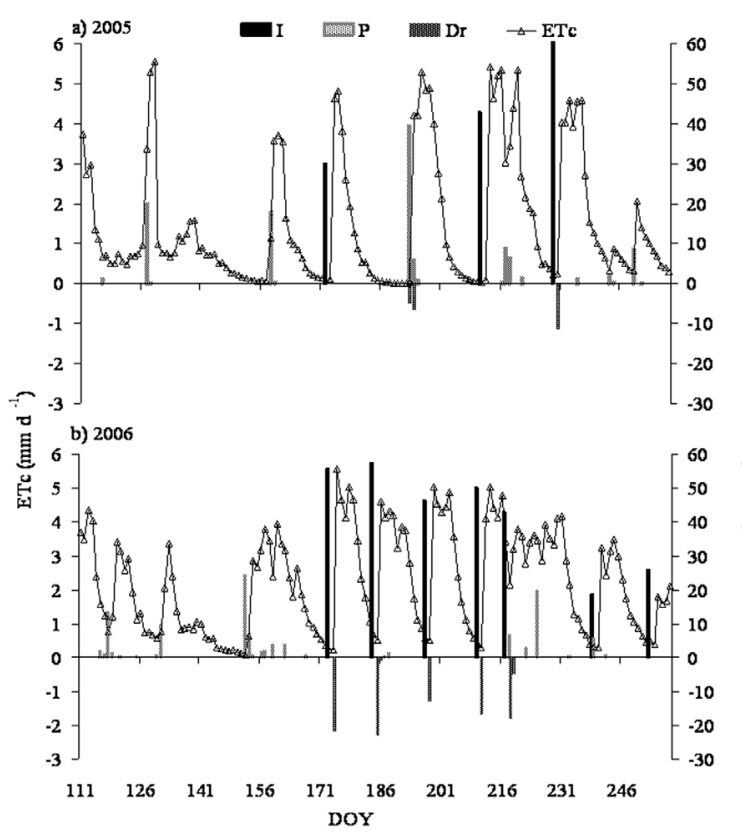

Figure 2. Daily values of rain (P), irrigation (I) drainage (Dr) and evapotranspiratin (ETc) of the vineyard during (a) 2005 and (b) 2006. lighted that in the case of "fixed-turn" irrigation, in the two years (2005 and 2006) the vineyard reached its maximum evapo-transpiration values $(>5 \mathrm{~mm} / \mathrm{d})$ right after the irrigations (or after precipitations). The daily ETc decreases in the interval between two contributions following water (by rain or irrigation). According to the adopted model, the ETc tends to be closer to 0 until new water contributions arise (Fig. 2).

In the case of "on demand" irrigation, in the course of the first year of activity (2005) the experimental relationship between $\Psi$ and available water in the soil was analysed. The practical indication deriving from this relationship is that, in the case of the soil studied, the leaf water potential's threshold in "pre-dawn" $(-0.4 \mathrm{MPa})$ is reached when the content of water in the first $0.5 \mathrm{~m}$ of the soil profile reaches $40 \mathrm{~mm}$ (Fig. 3). It must be underlined that the relationship between the pre-dawn leaf waterpotential and water in the soil has a "local" value; in other words it can be expanded towards similar pedological and cultural conditions.

In 2006 with "on demand" irrigation, $214 \mathrm{~mm}$ of water were distributed without losing water to drainage. In fact, on demand irrigation - guided by the plant's water status - allowed for water contributions with brief irrigation turns and volumes that were inferior $(20 \%)$ to those of "fixed-turned" irrigation (Tab. 3).

Comparing the $\Psi$ values measured during the vegetative season in 2006 for both irrigation management systems, it was evident that the "on demand" irrigated vineyard presented a better water status (Fig. 4). In this case the pre-dawn

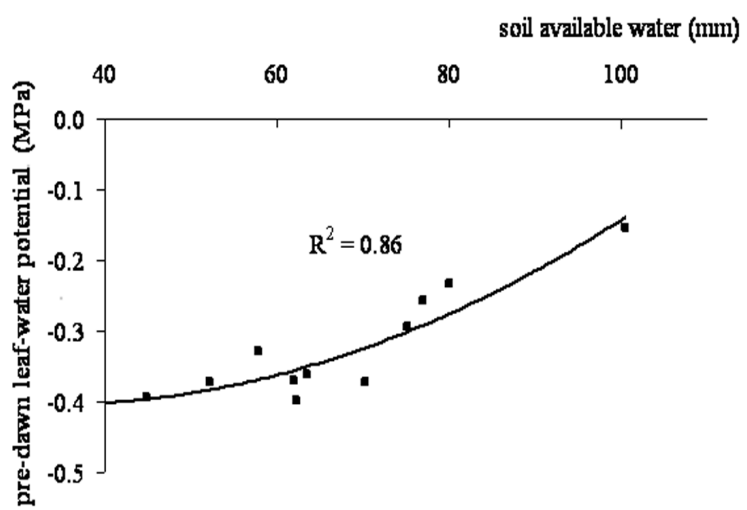

Figure 3. Relationship between pre-down leaf-water potential and soil available water in 2005 . The polynomial function is significant ( $\mathrm{p}<0.05$, data processed by General Linear Models). 
Table 3. Water balance in two vineyard fields during 2006: "fixed-turn" and "on demand" irrigation management.

\begin{tabular}{|c|c|c|}
\hline & \multicolumn{2}{|c|}{ Irrigation management } \\
\hline & "fixed-turn" & "on demand" \\
\hline Rain (mm) & \multicolumn{2}{|c|}{111,2} \\
\hline Irrigation (mm) & 296 & 214 \\
\hline $\operatorname{ETc}(\mathrm{mm})$ & 323 & 345 \\
\hline Drainage $(\mathrm{mm})$ & 95.7 & 0 \\
\hline
\end{tabular}

leaf water-potential of the vineyard according to fixed turns fell below $-0.5 \mathrm{MPa}$ five times in the course of the vegetative season, while the minimum pre-dawn leaf water-potential values measured in the "on demand" irrigated vineyard did not fall below the threshold value.

In particular, with fixed-turn irrigation, the vineyard received $408 \mathrm{~mm}$ of water (irrigation and rainfall) and lost $419 \mathrm{~mm}$ (evapo-transpiration and drainage) of which $28 \%$ was from drainage, which occurred after every irrigation (except for the last two ones when the volume was less than $26 \mathrm{~mm}$ ). In the case of on demand irrigation, however, the vineyard received $325 \mathrm{~mm}$ of water and lost $345 \mathrm{~mm}$ entirely due to evapo-transpiration (Tab. 3, Fig. 2).

From the operative point of view, using predawn leaf water-potential criterion to establish when to irrigate is to be excluded. In fact, these values are obtained by conducting arduous measurements taken manually before dawn, which are mainly used for research. Also, the use of $\Psi$ is valid in "semi-closed" soils (Tardieu and Katerji, 1991). In this case, the available water can be measured because the system has an impermeable lower boundary. Therefore, it is possible to establish relationships between $\Psi$ and AW. Nevertheless, these relationships are not stable. In fact, they can be modified according to the ability of the roots to explore the depth

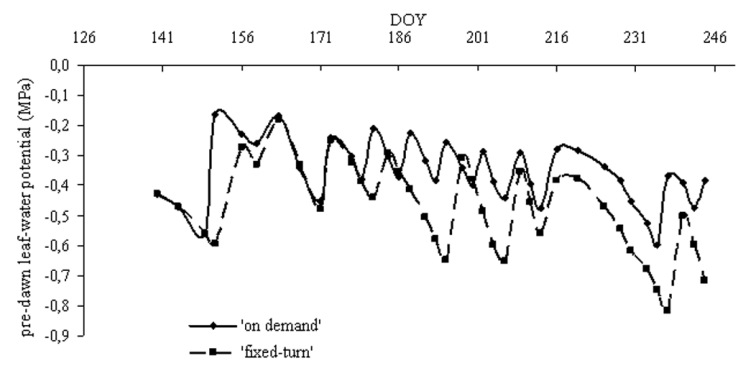

Figure 4. Pre-down leaf-water potential measured in 2006 on vineyard irrigated according the 'fixed-turn' and "on demand" irrigation management. of the soil. This aptitude depends on the species, the soil texture (Rasiah and Khol, 1989), the climatic demand (Denmead and Shaw, 1962), the chemical quality of the water (Katerji et al., 2003), and the chemical quality of the air (Bou Joudè et al., 2007). "Semi-closed" systems usually refer to plants which are cultivated in a pot or in lysymeter. In reality, it is possible to find this kind of system in the natural environment; for example, in the case of the shallow soils of Rutigliano (Rana and Katerji, 1996), but with crops having a superficial root system, and not that of a vineyard.

The case of grapevines cultivated in lithosoils with a cracked sub-layer of soil, corresponds to "open" soils (Tardieu and Katerji, 1991). These situations are verified when AW is not well-defined, because the non-rooted soil layer can contribute to water flow. In these conditions, the determination of the relationship between $\Psi$ and AW can be difficult to carry out.

Hence, different approaches are necessary to monitor the AW. Even irrigation scheduling of grapevines in "open" soil can be carried out by means of the water balance method in the hypothesis of defining the "equivalent depth".

Taking into consideration only the surface layer $(0.5 \mathrm{~m})$ of the soil (Fig. 5a), the daily ETc

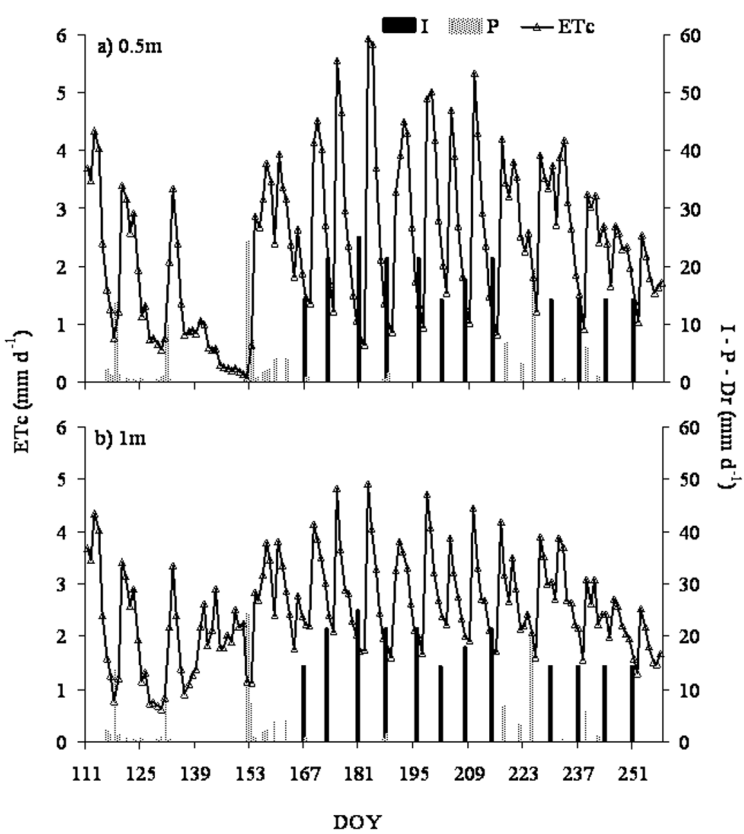

Figure 5. Daily values of rain (P), irrigation (I) drainage (Dr) and evapotranspiratin (ETc) of the vineyard during 2006. Irrigation management: "on demand"; depth of the soil: (a) $0,5 \mathrm{~m}$, (b) $1 \mathrm{~m}$. 


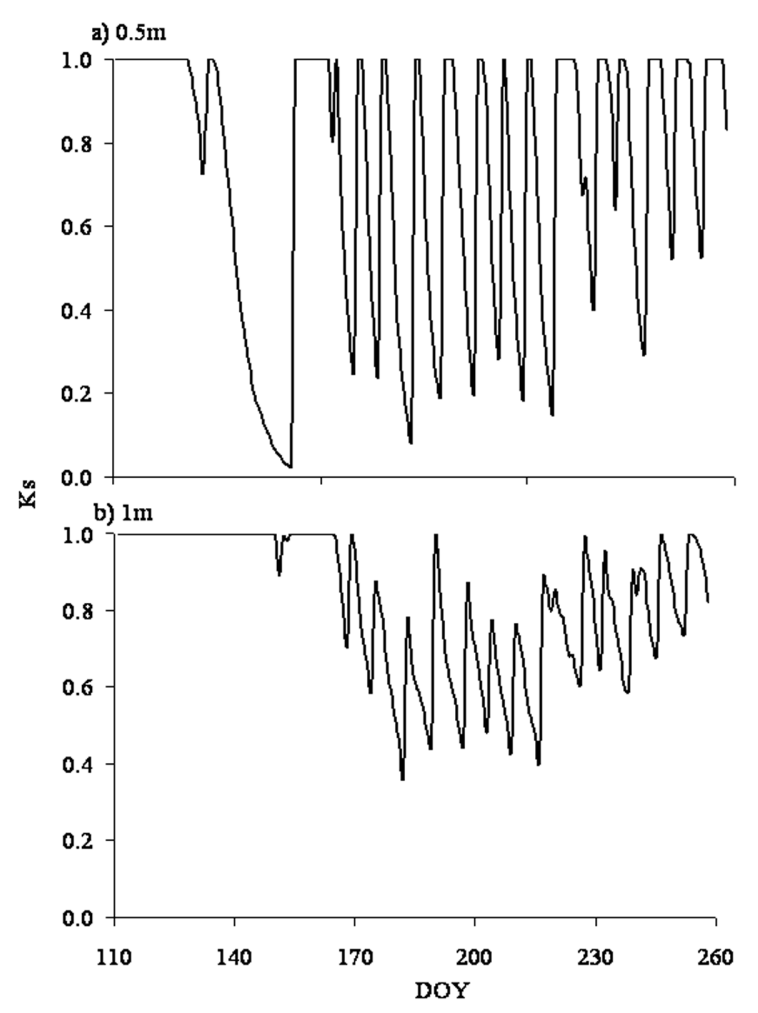

Figure 6. Values of Ks calculated during 2006 according the 'on demand' irrigation management, considering two soil depths: a) $0.5 \mathrm{~m}$, b) $1 \mathrm{~m}$.

values can measure less than $1 \mathrm{~mm}$ before every water intervention. These values are a sign of water stress. This condition, in fact, never took place on the crops.

Meanwhile, considering the water balance performed while taking into account the "equivalent depth" of $1 \mathrm{~m}$ (Fig. 5b), the daily ETc value varies from 5 to $2 \mathrm{~mm}$ during the interval between two consecutive irrigations. These values are similar for a table grapevine cultivated in the hinterlands of Bari (Campi et al., 2004), which does not undergo water deficit conditions.

Confirmation is obtained from the analysis of the water stress coefficient (Ks) values. Figure 6 highlights that the Ks values follow variations in the soil water content. Ks is equal to 1 after irrigation (maximum ETc) and decreases as the water in the soil dries up. When the water balance is carried out in a depth of $0.5 \mathrm{~m}$, $\mathrm{Ks}$ values which are close to zero (Fig. 6a) indicate water stress conditions which, in reality, were not observed during the experimentation period. In fact, with the water balance method which considers the "equivalent" depth of $1 \mathrm{~m}$,
Ks does not ever reach a value below 0.4 (Fig. $6 b)$. The plant did not even undergo enough stress to compromise its growth.

\section{Conclusions}

Table grape cultivation is common primarily in areas of Southern Italy with litho-soils, characterized by the presence of a reduced soil layer derived from a cracked calcareous rock which is sometimes present until the soil surface.

These pedological conditions do not make irrigation planning easy due to the difficulty of monitoring the water status of both the surface layer of the soil that is $0.5 \mathrm{~m}$ deep (because of the abundant presence of stones) and the rocky subsoil where the sacks of soil contribute to the water nutrition of the vineyard. Even monitoring the plant water status by surveying the xylematic leaf water-potential in pre-dawn is excluded due to the difficulty of establishing a relationship with the available water in the soil explored by the roots.

Therefore, since the depth of the roots and the volume of the explored soil are indeterminable, it is suggested to establish the irrigation scheduling through water balance. This criterion has proved to be promising when defining the depth of the zone explored by the root system, not on the basis of the first soil layer, but rather on the "equivalent depth".

In prospective, the evapo-transpiration estimates - and consequently the water balance and measurements of the water volumes in particularly difficult soils, such as litho-soils - could improve when adopting $\mathrm{Kc}$ values measured through experimentation, rather than those documented in literature.

The progress of irrigation studies allows for optimizing the water use, but the main limitation consists in irrigation water management. In fact, the obtained results demonstrate that, in respect to "fixed-turn" irrigation, "on demand" irrigation management allows for the reduction of $20 \%$ water volumes, without losing water to drainage and without compromising production (40 t/ha).

\section{References}

Allen R.G. et al. 1998. Crop evapotranspiration: guidelines for computing crop water requirements. Irrigation and Drainage. paper No. 56, FAO, Rome, 300 p. 
Bou Joudè M., Katerji N., Mastrorilli M., Rana G. 2007. Analysis of the oxone effect on soybean in the mediterranean region. I - The conseguences on cropwater status. Eur. J. Agron., 28:508-518.

Campi P., Colucci R., Di Bari V., Mastrorilli M. 2004. Variabilità interannuale dei volumi irrigui stagionali in Puglia. Rivista Italiana di Agrometeorologia, 8, 1:16-17.

Colapiatra M. 2004. L'uva da tavola, la coltura, il mercato, il consumo. Edagricole, 382 p.

Denmead O.T., Shaw R.H. 1962. Avaiability of soil water to plants as affected by soil moisture content and meteolological conditions. Agron. J., 54:383-389.

Doorenbos J. 1976. Agrometeorological field station FAO Irrigation and Drainage, paper 27, Rome, 94 p.

Katerji N., van Hoord J.W., Hamdy A., Mastrorilli M. 2003. Salinity effect on crop development and yield, analysis of salt tolerance according to several classification methods. Agr. Water manage., 62:37-66.

Lebon E., Dumas V., Piéri P., Shultz R.H. 2003. Model- ling the seasonal dynamics of the soil water bilance of vineyards. Functional Plant Biology, 30:699-710.

Palumbo A.D., Colucci R., Campi P., Marrone G., Mastrorilli M. 2007. Caratterizzazione dello stato idrico dei litosuoli per la programmazione irrigua di vigneti di uva da tavola. Atti di convegno, SISS, Bari, 21-24 giugno 2005, 308-315

Pellegrino A., Lebon E., Voltz M., Wery J. 2004. Relationships between plant and soil water status in vine (Vitis vinifera L.). Plant Soil, 266:129-142.

Rana G., Katerji N. 1997. A measurement based sensitivity analysis of the Penman-Monteith actual evapotranspiration model for crops of different height and in contrasting water status. Theor. Appl. Climatol., 60:141-149.

Rasiah V., Khol R.A. 1989. Soybean root uptake in two soil. Agr. Water Manage., 15:387-393.

Tardieu F., Katerji N. 1991. Plant response to the soil water reserve: consequences of the root system environment. Irrigation Sci., 12:193-197. 
